\title{
Vitamin D Levels in Full-Term Neonates with Indirect Hyperbilirubinemia
}

\author{
Neveen T. Abed ${ }^{1}$, Farida F. Negm ${ }^{1}$, Enas S. Ahmad ${ }^{2}$, Heba A. Mohammed ${ }^{* 1}$
}

Departments of ${ }^{1}$ Pediatric and ${ }^{2}$ Clinical and Chemical Pathology, Faculty of Medicine, Benha University, Egypt

*Corresponding author: Heba A. Mohammed, Mobile: (+20)01122803949, E-Mail: heba.anwar.soliman@ gmail.com

\begin{abstract}
Background: Jaundice is a common clinical sign in neonatal medicine. Considering the different roles of vitamin D, its lower level may be correlated with neonatal jaundice. Objectives: This study aimed to demonstrate the relationship between serum vitamin D level and neonatal hyperbilirubinemia and to measure its level in their mothers. Subjects and methods: This case-control study was conducted on 90 neonates and their mothers, 60 neonates with hyperbilirubinemia in patients group and 30 healthy neonates age and sex matched in control group. Blood samples from neonates and their mothers were obtained and sent for laboratory estimation of 25 -hydroxy vitamin D, calcium, magnesium, phosphorus, alkaline phosphatase and parathyroid hormone. Results: There is highly significant decrease of vitamin D levels among patients than controls, significant negative correlation between vitamin D levels and serum bilirubin in neonates and no significant difference regarding different laboratory parameters among their mothers. Conclusion: Decreased levels of vitamin D were significantly correlated with neonatal indirect hyperbilirubinemia so, low vitamin $\mathrm{D}$ can be included among risk factors for neonatal jaundice.
\end{abstract}

Keywords: Jaundice, Mothers, Neonatal, Vitamin D.

\section{INTRODUCTION}

Hyperbilirubinemia is one of the most common conditions in neonatal period. Discharge of healthy neonates early after birth, especially if breastfeeding is not well established, may lead to delayed diagnosis of pathological hyperbilirubinemia that has the ability for causing neurological complications ${ }^{(1)}$. Overall, up to $60 \%$ of term neonates have significant jaundice in the $1^{\text {st }}$ week of life ${ }^{(2)}$. Any problem which increases bilirubin production and decreases conjugation can cause neonatal jaundice ${ }^{(3)}$.

It is necessary to know different risk factors for increased incidence of neonatal jaundice because its incidence can be reduced by modifying them. Vitamin $\mathrm{D}$ is fat-soluble vitamin technically considered a hormone. Different functions of vitamin D were reported in medical research ${ }^{(4)}$.

Vitamin D in the body comes from dietary sources and from synthesis in the skin exposed to sun light. Ultraviolet irradiation stimulates skin synthesis of cholecalciferol, then hydroxylation in the liver to 25hydroxyl vitamin $\mathrm{D} \quad(25-(\mathrm{OH}) \quad \mathrm{D})$ and lastly hydroxylation in the kidney to the active form, 1, 25 dihydroxy vitamin $\mathrm{D}^{(5)}$.

Vitamin D deficiency is a worldwide problem. Insufficiency and deficiency of vitamin D has been related to multiple diseases, ranging from neurological disorders to chronic inflammatory conditions ${ }^{(6)}$. Decreased vitamin D causes marked damages to the growth and development of fetal bones ${ }^{(7)}$.

Although vitamin D metabolism and bilirubin metabolism occurs on two separated pathways, both of them have a common pathway in the liver. So, changes in synthesis or metabolism of each of them might have an effect on the other product ${ }^{(2)}$, so this study aimed to demonstrate the relationship between serum vitamin $\mathrm{D}$ level and neonatal hyperbilirubinemia and to measure its level in their mothers.

\section{SUBJECTS AND METHODS}

This case-control study was conducted on 90 neonates, recruited from Neonatal Intensive Care Units (NICU) of Benha University Hospital and their mothers in the period from October, 2018 till October, 2019.

Ethical approval: Approval of the Research Ethics Committee at Benha University Hospital, Faculty of Medicine was obtained. A written consent was collected from parents to agree to participate in the study.

Inclusion criteria: Full-term neonates with gestational age $\geq 37$ weeks, exclusive breast feeding, with indirect hyperbilirubinemia that was needed phototherapy according to American Academy of pediatrics ${ }^{(\mathbf{8})}$.

Exclusion Criteria: Neonates with pathological causes for their hyperbilirubinemia such as: $\mathrm{ABO}$ and $\mathrm{Rh}$ incompatibility, sepsis, glucose- 6 phosphate dehydrogenase deficiency, cephalhematoma, Jaundice necessitating exchange transfusion, perinatal asphyxia and congenital anomalies. Also newborns whose mothers had a history of chronic disorders such as: hepatic disorders, kidney disorders, gestational diabetes, hypertension, anticonvulsant therapy, malignancy, cardiovascular diseases, diabetes mellitus, respiratory diseases, autoimmune diseases and musculoskeletal diseases were excluded.

\section{They were divided in two groups:}

Patients group: included 60 term neonates with indirect hyperbilirubinemia needing phototherapy.

Control group: included 30 healthy neonates with similar age and sex.

Each neonate in this study was subjected to complete history taking, full clinical examination, also their mothers were asked about their age, educational state, calcium and vitamin D use during pregnancy and any disease or drug intake that might affect vitamin $\mathrm{D}$ 
levels. Maternal body mass index (BMI) was calculated by (weight in kilogram divided by square of height in meters).

Laboratory investigations for neonates before starting phototherapy included complete blood count $(\mathrm{CBC}), \mathrm{C}$ reactive protein (CRP), serum bilirubin, serum calcium $(\mathrm{Ca})$, magnesium $(\mathrm{Mg})$, phosphorus $(\mathrm{P})$, alkaline phosphatase (ALP), parathyroid hormone (PTH) and 25-hydroxy vitamin D were measured, also mothers' Ca, P, ALP, Mg, PTH and 25-hydroxy vitamin $D$ were estimated.

\section{Study measurement:}

Skin was rubbed with antiseptic and $6 \mathrm{ml}$ of venous blood were taken from newborn. $1 \mathrm{ml}$ was collected in a test tube containing $50 \mu \mathrm{l}$ of EDTA and analyzed as soon as possible for reticulocytes count and using (Phonex 3300, China) cell counter for CBC count and 5 $\mathrm{ml}$ of blood was collected in a plain test tube, left to clot, then centrifuged for 10 minutes at $1500 \mathrm{rpm}$. Serum was separated and stored at $-40^{\circ} \mathrm{C}$ for quantitative measurement of CRP, total serum bilirubin and direct bilirubin, serum calcium, magnesium, phosphorus, alkaline phosphatase, parathyroid hormone and 25hydroxy vitamin D.

Regarding, their mothers $5 \mathrm{ml}$ of venous blood were taken for serum calcium, magnesium, phosphorus, alkaline phosphatase, parathyroid hormone and 25hydroxy vitamin D. Measurement of serum total bilirubin and direct bilirubin were converted to color azobilirubin by diazotized sulfanilic acid and measured photometrically. The color intensity is proportional to the bilirubin concentration in the sample at wave length 578. Measurement of CRP was depending on the reaction between (CRP) and latex covalently bound antibodies against human CRP. CRP values were estimated photometrically at wave length 546. Measurement of serum calcium was at a neutral $\mathrm{pH}, \mathrm{Ca}$ form with arsenazo-III complex, the color intensity was directly proportional to the concentration of calcium in the sample. Measurement of serum magnesium was based on forming a colored chelate complex when reacting with xylidyl blue in alkaline solution, the color intensity is proportional to the magnesium concentration. Measurement of serum phosphorus was based on the reaction of the inorganic phosphate with ammonium molybdate in presence of sulfuric acid to form non reduced phosphomolybdate.

The concentration of phosphomolybdate formed was directly proportional to the inorganic phosphate concentration. It is determined by measuring the increase in absorbance at $340 \mathrm{~nm}$. All the chemical reacts were done by (Biosysim A15, company, Spain). Measurement of serum 25-hydroxyvitamin D was based on a competitive enzyme linked immunosorbent assay (ELISA) (Sun Red Biotechnology, China). The levels of vitamin $\mathrm{D}$ was defined as: The normal level is (2060) $\mathrm{ng} / \mathrm{ml}$, insufficiency is $(15-19.9) \mathrm{ng} / \mathrm{ml}$, deficiency is $(5-14.9) \mathrm{ng} / \mathrm{ml}$, and severe deficiency is $<5 \mathrm{ng} / \mathrm{ml}^{(9)}$.

\section{Statistical analysis}

The data were analyzed using SPSS version 16 software (SPSS Inc, Chicago, ILL Company). Categorical data were presented as number and percentages. Chi square test $\left(\mathrm{X}^{2}\right)$ or Fisher's exact test (FET) were used to analyze categorical variables. Quantitative data were expressed as mean \pm standard deviation. Student " $t$ " test was used to analyze normally distributed variables among 2 independent groups.

While non-parametric variables were analyzed using Mann-Whitney U tests. Spearman's correlation coefficient (rho) was used to assess liner association between variables. ROC curve was used to determine cutoff value of vitamin $D$ with optimum sensitivity and specificity in prediction of hyperbilirubinemia. $\mathrm{P}<0.05$ was considered significant.

\section{RESULTS}

The characteristic data of the patients in table (1) shows non-significant difference between patients and controls as regard gestational age, post-natal age, APGAR score at one minute, weight, head circumference (HC), length, sex and mode of delivery.

Table (1): The Demographic characteristics of the studied neonates.

\begin{tabular}{|c|c|c|c|}
\hline \multirow[t]{2}{*}{ Variable } & Patients group $(\mathrm{N}=60)$ & Controls group $(\mathrm{N}=30)$ & \multirow[t]{2}{*}{$\mathbf{P}$} \\
\hline & Mean \pm SD & Mean \pm SD & \\
\hline Gestational age (weeks) & $37.5 \pm 0.74$ & $37.4 \pm 0.62$ & $>0.05$ \\
\hline Post-natal age (days) & $4.3 \pm 1.60$ & $5.0 \pm 1.06$ & $>0.05$ \\
\hline APGAR score at one minute & $9.1 \pm 0.71$ & $9.2 \pm 0.80$ & $>0.05$ \\
\hline Weight (kg) & $3.03 \pm 0.18$ & $3.05 \pm 0.22$ & $>0.05$ \\
\hline $\mathrm{HC}(\mathrm{cm})$ & $34.1 \pm 0.93$ & $33.8 \pm 0.88$ & $>0.05$ \\
\hline Length (cm) & $50.4 \pm 1.05$ & $50.0 \pm 1.4$ & $>0.05$ \\
\hline \multirow{3}{*}{$\begin{array}{lc}\text { Sex } & \text { Male }(\mathrm{n}(\%)) \\
& \text { Female }(\mathrm{n}(\%)) \\
\text { Mode of delivery } & \text { NVD }(\mathrm{n}(\%))\end{array}$} & $29(48.3 \%)$ & $14(46.7 \%)$ & \multirow[t]{2}{*}{$>0.05$} \\
\hline & $31(51.7 \%)$ & $16(53.3 \%)$ & \\
\hline & $22(36.7 \%)$ & $12(40.0 \%)$ & \multirow[t]{2}{*}{$>0.05$} \\
\hline 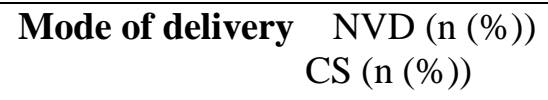 & $38(63.3 \%)$ & $18(60.0 \%)$ & \\
\hline
\end{tabular}

HC: Head Circumference. BMI: Body mass index. NVD: Normal Vaginal Delivery.

C/S: Cesarean Section. 
The mean demographic variables between the mothers of the patients and controls in table (2) shows nonsignificant difference between them as regard maternal age and maternal body mass index (BMI). There is statistically significant difference between patients and controls group as regard maternal education state and highly significant antenatal history of irregular and no intake of calcium and vitamin D among patients than controls.

Table (2): Comparison of the demographic variables between the mothers in the patients and control groups.

\begin{tabular}{|c|c|c|c|}
\hline Maternal data & Patients & Controls & $\mathrm{P}$ \\
\hline Maternal age (years) & $27.1 \pm 4.15$ & $27.0 \pm 2.85$ & $>0.05$ \\
\hline BMI $\left(\mathrm{kg} / \mathrm{m}^{2}\right)$ & $21.6 \pm 2.04$ & $22.0 \pm 1.73$ & $>0.05$ \\
\hline $\begin{array}{l}\text { Education } \\
\text { Illiterate }(\mathrm{n}(\%))\end{array}$ & \multirow{3}{*}{$\begin{array}{c}9(15.0 \%) \\
42(70.0 \%) \\
9(15.0 \%)\end{array}$} & \multirow{3}{*}{$\begin{array}{c}6(20.0 \%) \\
10(33.3 \%) \\
14(46.7 \%)\end{array}$} & \multirow{3}{*}{$0.002(\mathrm{~S})$} \\
\hline Less than high school (n (\%)) & & & \\
\hline High school (n (\%)) & & & \\
\hline Intake of Ca and vitamin D & \multirow{4}{*}{$\begin{array}{l}14(23.3 \%) \\
35(58.3 \%) \\
11(18.3 \%)\end{array}$} & \multirow{4}{*}{$\begin{array}{c}3(10.0 \%) \\
8(26.7 \%) \\
19(63.3 \%)\end{array}$} & \multirow{4}{*}{$<0.001(\mathrm{HS})$} \\
\hline No $(\mathrm{n}(\%))$ & & & \\
\hline Irregular (n (\%)) & & & \\
\hline Regular (n (\%)) & & & \\
\hline
\end{tabular}

BMI: Body mass index. S = Significant. HS: Highly significant

Comparison of the mean laboratory parameters in the patients and controls in table (3) shows highly significant increase in serum total and direct bilirubin in patients than controls, highly significant decrease in 25 hydroxy vitamin D in patients than controls and highly significant presence of (insufficiency, deficiency and sever deficiency) of 25 hydroxy vitamin $\mathrm{D}$ levels among patients than controls but there is non-significant difference between patients and controls group as regard Hb, TLC, Retics ,serum Ca, P, ALP, Mg, and PTH.

Table (3): The laboratory parameters in the patients and controls group.

\begin{tabular}{|c|c|c|c|}
\hline \multirow{2}{*}{ Variable } & $\begin{array}{c}\text { Patients group } \\
(\mathrm{N}=60)\end{array}$ & $\begin{array}{c}\text { Control group } \\
(\mathbf{N}=\mathbf{3 0})\end{array}$ & \multirow{2}{*}{$\mathbf{P}$} \\
\hline & Mean \pm SD & Mean \pm SD & \\
\hline Hb (gm/dl) & $14.7 \pm 1.03$ & $15.2 \pm 1.13$ & $>0.05$ \\
\hline TLC $\left(\mathbf{x 1 0 ^ { 3 }}\right)$ & $11.0 \pm 3.99$ & $10.5 \pm 1.90$ & $>0.05$ \\
\hline Retics & $0.6 \pm 0.70$ & $0.94 \pm 0.51$ & $>0.05$ \\
\hline Total bilirubin (mg/dL) & $18.2 \pm 3.03$ & $2.09 \pm 0.46$ & $<0.001(\mathrm{HS})$ \\
\hline Direct bilirubin (mg/dL) & $1.84 \pm 0.45$ & $0.52 \pm 0.16$ & $<0.001(\mathrm{HS})$ \\
\hline $\mathrm{Ca}(\mathrm{mg} / \mathrm{dl})$ & $9.1+0.6$ & $9.4 \pm 0.7$ & $<0.04(\mathrm{~S})$ \\
\hline$P(\mathrm{mg} / \mathrm{dl})$ & $5.0 \pm 1.2$ & $5.3 \pm 1.3$ & $<0.03(\mathrm{~S})$ \\
\hline $\operatorname{ALP}(\mathrm{U} / \mathrm{L})$ & $538.1+29.3$ & $446.6+11.4$ & $<0.002(\mathrm{~S})$ \\
\hline $\operatorname{Mg}(\mathbf{m g} / \mathbf{d l})$ & $1.8+0.1$ & $1.9+0.1$ & $<0.001$ (HS) \\
\hline PTH $(\mathrm{pg} / \mathrm{ml})$ & $54.5 \pm 5.8$ & $45.4 \pm 3.8$ & $<0.04(\mathrm{~S})$ \\
\hline 25-(OH) vitamin D (ng/ml) & $13.48 \pm 2.99$ & $27.55 \pm 1.63$ & $<0.001(\mathrm{HS})$ \\
\hline 25 hydroxy vitamin D level & \multirow{5}{*}{$\begin{array}{c}1(1.7 \%) \\
28(46.7 \%) \\
28(46.7 \%) \\
3(5.0 \%)\end{array}$} & \multirow{5}{*}{$\begin{array}{c}29(96.7 \%) \\
1(3.3 \%) \\
0(0.0 \%) \\
0(0.0 \%)\end{array}$} & \multirow{5}{*}{$<0.001(\mathrm{HS})$} \\
\hline Normal (20-60) ng/ml (n (\%)) & & & \\
\hline Insufficiency (15-19.9) ng/ml (n (\%)) & & & \\
\hline Deficiency (5-14.9) ng/ml (n (\%)) & & & \\
\hline Severe deficiency $(<5) \mathrm{ng} / \mathrm{ml}(\mathrm{n}(\%))$ & & & \\
\hline
\end{tabular}

S: significant. HS: Highly significant

Comparison of the mean laboratory parameters in the mothers of patients and controls in table (4) shows nonsignificant difference between them as regard 25-hydroxy vitamin D, serum Ca, P, ALP, Mg, and PTH (P >0.05). 
Table (4): The laboratory parameters in the mothers of both patients and controls group.

\begin{tabular}{|c|c|c|c|}
\hline \multirow{2}{*}{ Variable } & $\begin{array}{c}\text { Patients group } \\
(\mathrm{N}=60)\end{array}$ & \begin{tabular}{|c|c} 
Control group \\
$(\mathbf{N}=\mathbf{3 0})$
\end{tabular} & \multirow{2}{*}{$\mathbf{P}$} \\
\hline & Mean \pm SD & Mean \pm SD & \\
\hline 25-(OH) vitamin D (ng/ml) & $24.02 \pm 2.07$ & $28.03 \pm 6.69$ & $>0.05$ \\
\hline $\mathrm{Ca}(\mathrm{mg} / \mathrm{dl})$ & $9.4 \pm 0.6$ & $9.2 \pm 0.7$ & $>0.07$ \\
\hline$P(\mathrm{mg} / \mathrm{dl})$ & $4.6 \pm 1.0$ & $5.1 \pm 1.5$ & $>0.05$ \\
\hline $\operatorname{ALP}(\mathbf{U} / \mathbf{L})$ & $386.3 \pm 22.5$ & $299.7 \pm 46.0$ & $<0.04(\mathrm{~S})$ \\
\hline $\operatorname{Mg}(\mathrm{mg} / \mathrm{dl})$ & $1.8 \pm 0.2$ & $1.8 \pm 0.1$ & $>0.05$ \\
\hline PTH (pg/ml) & $50 . \overline{5+6.4}$ & $45.4+9.1$ & $>0.05$ \\
\hline
\end{tabular}

S: significant.

Table (5) shows that vitamin D at a cut off value $\leq 20.07 \mathrm{pg} / \mathrm{ml}$ had high sensitivity and specificity in prediction of hyperbilirubinemia in full-term neonates.

Table (5): Performance characters of 25-hydroxy vitamin D (ng/ml) in prediction of hyperbilirubinemia in full term neonates:

\begin{tabular}{|c|l|l|l|l|l|l|l|c|}
\hline $\begin{array}{c}\text { 25-hydroxy } \\
\text { vitamin D }\end{array}$ & Sens\% & Spec\% & PPV\% & NPV\% & $\begin{array}{c}\text { Accuracy } \\
\text { \% }\end{array}$ & AUC & $\begin{array}{c}\text { 5\% CI of } \\
\text { AUC }\end{array}$ & P \\
\hline $\begin{array}{c}\leq 20.07 \\
(\mathrm{ng} / \mathrm{ml})\end{array}$ & $98.3 \%$ & $96.7 \%$ & $98.3 \%$ & $96.7 \%$ & $96.7 \%$ & 0.994 & $0.98-1.0$ & $\begin{array}{c}<0.001 \\
(\mathrm{HS})\end{array}$ \\
\hline
\end{tabular}

HS: Highly significant

Figure (1) shows significant negative correlation between neonatal 25-hydroxy vitamin D levels and serum total bilirubin.

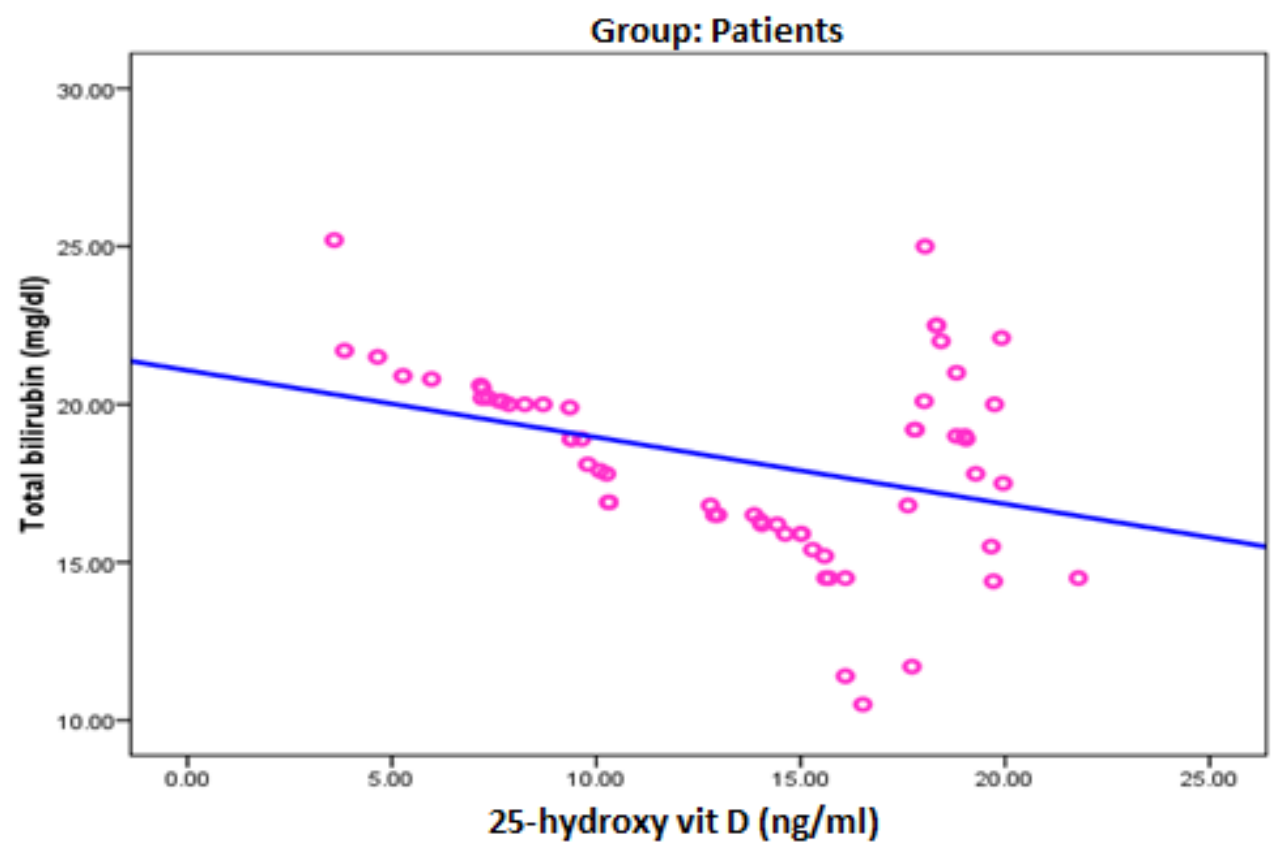

Fig. (1): Correlation between total bilirubin and 25-hydroxy vitamin D (pg/ml) levels. 


\section{DISCUSSION}

There are several recognized causes of neonatal hyperbilirubinemia; however, in several studies, the cause remain unknown in $10-50 \%$ of infants hospitalized with jaundice. Considering the different functions of vitamin $\mathrm{D}$, its low level may be related to neonatal jaundice ${ }^{(2)}$. In this study, there were no significant differences between patients and controls as regard gestational age, postnatal age, sex and mode of delivery. We found no significant difference between both groups as regard length, weight and head circumference, and this is in agreement with Mutlu et al. (10) study in China which studied the relationship between serum vitamin D level and the hyperbilirubinemia in full term neonates, and Aletayeb et $\boldsymbol{a l} .{ }^{(2)}$ study in Iran which compared between maternal and neonatal serum vitamin $\mathrm{D}$ levels in term jaundiced and non-jaundiced cases but Ismail et al., (11) study which investigates vitamin $\mathrm{D}$ levels in neonatal hyperbilirubinemia in Menoufia, Egypt, found that there is highly significant increase in head circumference among patients than controls.

Sathish et al. ${ }^{(12)}$ study reported that there was statistically significant correlation between neonatal vitamin D level, body length, head circumference and chest circumference. They found significant correlation between maternal and cord blood levels of 25-hydroxy vitamin D. Vitamin D deficiency in mothers had been associated with adverse pregnancy outcome. Transplacental passage of maternal vitamin $\mathrm{D}$ is the only source of vitamin $\mathrm{D}$; accordingly, pregnant women should receive vitamin D to ensure enough levels of vitamin $\mathrm{D}$ in their baby adequate for the first 4-6 months of life.

Regarding maternal age and BMI, our study found no significant difference between patients and controls, this is in agreement with Mutlu et al. ${ }^{\left({ }^{10)}\right.}$ and Ismail et al. ${ }^{(11)}$ studies, but Bowyer et al. ${ }^{(13)}$ study revealed that the risk of vitamin D deficiency was higher among young pregnant women below 30 years old, also Aletayeb et al. ${ }^{(2)}$ study revealed that the body mass index (BMI) for the mothers of patient group was significantly higher than that for the mothers in the control group.

Williams et al. ${ }^{(14)}$ reported that vitamin D is fat soluble and is stored in adipose tissue, and may be sequestered in a larger body pool of fat of obese individuals. People obtain most of their vitamin D requirement from exposure to sunlight. It has been shown that there is more than 50\% decreased bioavailability of skin synthesized vitamin D3 in obese adult subjects and this likely accounts for the consistent observation that obesity is associated with vitamin D deficiency.

In this current study, there is significant increase in patients among illiterate mothers and this is in agreement with Ismail $\boldsymbol{e t} \boldsymbol{a l} .{ }^{(11)}$ and El Rifaia $\boldsymbol{e t}$ al.
(15) study in Egypt, which found significant correlation between, vitamin D level and educational level of the mothers; this is mostly linked to better knowledge of vitamin D rich diet in highly educated women but Gur et al. (16) found non-significant difference as regard maternal education state.

In our study there is statistically significant positive maternal antenatal history of irregular and no intake of calcium and vitamin $\mathrm{D}$ among patients than controls, which is similar to Gur et al. ${ }^{(16)}$, Pérez-López et al. ${ }^{(17)}$,_Cetinkaya et al..$^{(18)}$ and Ismail et al. ${ }^{(11)}$ but Mutlu et al. (10) found statistically non-significant difference between the two studied groups as regard of maternal antenatal history of intake calcium and vitamin $\mathrm{D}$.

In our study, we found statistically nonsignificant difference between patients and controls and their mothers as regard serum $\mathrm{Ca}, \mathrm{P}, \mathrm{ALP}, \mathrm{Mg}$, and PTH, and this is in agreement with Mutlu et al. ${ }^{(10)}$ and Aletayeb et al. ${ }^{(2)}$. This can be explained by the short duration of vitamin $D$ insufficiency or deficiency in patients group and normal mothers' vitamin D levels corroborate this.

In our study, there is highly significant increase in bilirubin level in patients than controls, highly significant decrease in serum vitamin D level among patients than controls and significant negative correlation between serum total bilirubin and vitamin $\mathrm{D}$ level but no significant difference in vitamin D among their mothers and this in agreement with Aletayeb et al. (2) who reported that newborn vitamin D levels were significantly lower among jaundiced cases than controls, this may demonstrate an association between indirect hyperbilirubinemia and serum vitamin D levels. Vitamin D metabolism and bilirubin metabolism were performed on two different pathways, both had a common step in the liver, so any change in synthesis or metabolism of any one of them might have an effect on the other product.

Bhat et al. ${ }^{(4)}$ study in India, which investigated the correlation of 25 hydroxy vitamin D levels with neonatal hyperbilirubinemia in term healthy newborn, reported that term healthy newborns have significantly decreased vitamin D levels and show a negative correlation with neonatal hyperbilirubinemia, thus decreased vitamin $\mathrm{D}$ can be included among the risk factors for neonatal jaundice.

Also Ismail et al. ${ }^{(11)}$ and Mutlu et al. ${ }^{(10)}$ studies revealed high significant decrease in vitamin D among hyperbilirubinemic patients than control. Mutlu et al. ${ }^{(10)}$ recorded that low antioxidant system may enhance the severity of neonatal hyperbilirubinemia.

Elfarargy et al. ${ }^{(19)}$ study in Tanta investigated serum levels of vitamin $C, D$ and $E$ in neonatal jaundice and revealed lower serum levels of vitamin $\mathrm{C}, \mathrm{D}$ and $\mathrm{E}$ in jaundiced than controls and recorded that vitamin $\mathrm{D}$ had a protective function in the liver through anti- 
inflammatory effect and the liver plays an important role in detoxification of indirect bilirubin to direct bilirubin and hence vitamin $\mathrm{D}$ should have a role in helping the liver to decrease neonatal jaundice. Jahanjoo et al. (20) study recommend that mothers should receive vitamin $\mathrm{D}$ to decline the levels of bilirubin in their neonates.

In contrast to our study Mehrpisheh et al $^{\left({ }^{(3)}\right.}$ study in Iran found the lack of an association between vitamin $\mathrm{D}$ level and neonatal hyperbilirubinemia, as their groups were homogenized in terms of their demographic variable socioeconomic status and maternal risk factors.

\section{CONCLUSION}

Decreased levels of vitamin D were significantly correlated with neonatal indirect hyperbilirubinemia so, low vitamin D can be included among risk factors for neonatal jaundice.

\section{RECOMMENDATIONS}

Study the role of vitamin D supplementations as an adjuvant treatment in neonatal hyperbilirubinemia.

Conflicts of Interest: The authors declare that they have no conflicts of interest.

\section{REFERENCES}

1. Romagnoli C, Barone $G$ and Pratesi $S$ et al. (2014): Italian Guidelines for Management and Treatment of Hyperbilirubinaemia of Newborn Infants $\geq 35$ weeks' Gestational Age. Italian Journal of Pediatrics, 40 (1): 11 16.

2. Aletayeb S, Dehdashtiyan M, Aminzadeh $\mathrm{M}$ et al.(2016): Comparison Between Maternal and Neonatal Serum Vitamin D Levels in Term Jaundiced and nonJaundiced cases. J Chin Med Assoc., 79: 614-617.

3. Mehrpisheh S, Memarian A, Mahyar A et al. (2018): Correlation between Serum Vitamin D Level and Neonatal Indirect Hyperbilirubinemia. Doi:10.1186/s12887-018-1140-9.

4. Bhat J, Sheikh S, Ara R (2019): Correlation of 25Hydroxy Vitamin D Level with Neonatal Hyperbilirubinemia in Term Healthy Newborn: A prospective Hospital-based Observation study. https://www.sciencedirect.com/science/article/pii/S2352 646719302017

5. Spiro A, Buttriss J (2014): Vitamin D: An overview of Vitamin D Status and Intake in Europe. Nutrition Bulletin, 39 (4): 322-350.

6. Zhang H, Shih D, Zhang $X$ (2013): Mechanisms Underlying Effects of 1, 25-Dihydroxy Vitamin D3 on the Th17 Cells. Eur J Microbiol Immunol., 3 (4): 237-40.
7. Nair R, Maseeh A (2012): Vitamin D: The Sun shine Vitamin. Journal of Pharmacology \& Pharmacotherapeutics, 3 (2): 118-126.

8. American Academy of Pediatrics Subcommittee on Hyperbilirubinemia (2004): Management of hyperbilirubinemia in the newborn infant 35 or more weeks of gestation. Pediatrics, 114: 297-316.

9. Misra M, Pacaud D, Petryk A et al. (2008): Vitamin D deficiency in children and its management: review of current knowledge and recommendations. Pediatrics, 122: 398-417.

10. Mutlu M, Cayir A and Cayir Y et al. (2013): Vitamin D and Hyperbilirubinaemia in Neonates. HK J Paediatr, 18, 77- 81.

11. Ismail H, El Mashad G, El- Shafie M et al. (2018): Vitamin D Levels in Neonatal Hyperbilirubinemia. Thesis (M.S.) - Minoufiya University. Faculty of Medicine, Pediatrics Dept., 618: 92-98.

12. Sathish P, Raveendran S, Padma $R$ et al. (2016): Correlation between Maternal and Neonatal Blood Vitamin D Levels and its Effect on the Newborn Anthropometry. Int J Reprod Contracept Obstet Gynecol., 5(9): 2983-2988.

13. Bowyer L, Catling - Paull C, Diamond T et al. (2009): Vitamin D, PTH and Calcium levels in pregnant women and their neonate's. Clin. Endocrinol (Oxf), 70 (3): $372-$ 7 .

14. Williams R, Novick M, Lehman E (2014): Prevalence of Hypovitaminosis D and Its Association with Comorbidities of Childhood Obesity. Perm J,, 18: 32-39.

15. El Rifai N, Abdel Moety G, Gaafar H (2013): Vitamin D Deficiency in Egyptian Mothers and their Neonates and Possible Related Factors. The Journal of Maternal-Fetal \& Neonatal Medicine, 27(10): 1064-1068.

16. Gur G, Abaci A, Koksoy A et al. (2014): Incidence of Maternal Vitamin D Deficiency in A region of Ankara, Turkey: A preliminary Study. Turkish Journal of Medical Sciences, 44: 616-623.

17. Pérez-López F, Pasupuleti V, Mezones-Holguin E et al. (2015): Effect of Vitamin D Supplementation during Pregnancy on Maternal and Neonatal Outcomes: A systematic Review and Meta-Analysis of Randomized Controlled Trials. Fertility and Sterility, 103(5): 12781288.

18. Cetinkaya M, Cekmez F, Buyukkale G et al. (2015): Lower Vitamin D Levels are Associated with Increased Risk of Early-Onset Neonatal Sepsis in Term Infants. Journal of Perinatology, 35: 39-45.

19. Elfarargy MS, Ali DA and Al-Ashmawy GM et al. (2019): Detection of Serum Levels of Vitamin C, D and E in Neonatal Jaundice. Journal of Clinical Neonatology, 8 (4): 222-226.

20. Jahanjoo F, Farshbaf-khalili A, Shakourisk $S$ et al. (2018): Maternal and Neonatal Outcomes of Vitamin D Supplementation in Gestational Diabetes Mellitus: A systemic Review and Meta-Analysis. Ann Nutr Metab., 73: $145-159$. 